Original Research Paper

\title{
Antecedents of Employees' Turnover Intentions: Evidence from Private Educational Institutions
}

\author{
Atif Atique Siddiqui and Raja Ahmed Jamil \\ Department of Management Sciences, University of Haripur, Pakistan
}

\author{
Article history \\ Received: 17-08-2015 \\ Revised: 11-09-2015 \\ Accepted: 22-09-2015 \\ Corresponding Author: \\ Raja Ahmed Jamil \\ Department of Management \\ Sciences, University of \\ Haripur, Pakistan \\ Email: raja.ahmed@uoh.edu.pk
}

\begin{abstract}
In today's competitive environment, the development and retention of human capital has become a serious concern for organizations. This study aims to study the antecedents of employees' turnover intentions in private educational institutions. A closed ended questionnaire was distributed among 200 employees of different educational institutions. One hundred and seventy eight of them responded with total response rate of $79 \%$. Regression analyses were performed to test the hypotheses set forth. The findings of the study revealed that turnover intentions are influenced by job stress and work environment whereas work overload has not been found as a significant predictor of turnover intentions.
\end{abstract}

Keywords: Job Stress, Work Overload, Work Environment, Turnover Intentions, Private Educational Institutions

\section{Introduction}

Stress is the word that almost everybody is familiar with. Every person in the world is exposed to stress in one way or the other with varying degrees. However, as it keeps increasing, it tends to become more and more problematic and difficult to handle. In an organizational context, coping with stress has become one of the most important issues. In today's highly competitive environment, the phenomenon of stress has become very common. Challenging demands of the work today have put excessive pressures on employees which causes them to feel exhaustion and nervous tension. Consequently their performance at work suffers. Research shows that stress substantially impacts job performance and organizations are trying to find ways to cope effectively with such trying situations (Anderson, 2003). Similarly work load may prove to be a high risk to an employee's health (Biron et al., 2008). The workplace environment may also be a source of satisfaction or dissatisfactions for an employee. A lot of research has been made on the aforesaid issues where these have proved to be the major contributing factors to the employees' turnover rate. Researchers have previously related these factors to the turnover intentions (Qureshi et al., 2012).

The purpose of this study is to focus the private educational sector of Pakistan to determine whether the same equation exists or not. The number of private educational institutions is on the rise with every passing day and future of a major section of society is attached to it. This study may have important implications for the government functionaries and the concerned lot for bringing about meaningful improvements in the effective functioning of the private educational sector for the welfare and good of the society. The results of this study will play an important role for managers and those at the helm of affairs of such institutions to take due care of the job stress, work load and work environment of their employees. Furthermore, it may be useful for the governments to devise such a service structure for the private institutions that can enhance the efficiency and effectiveness of workers and ultimately improve the level of education in the country.

\section{Literature Review}

\section{Stress}

Stress refers to the pressure or tension exerted on a material object. It is the body's way of responding to a challenge. In literature, it has been expressed in numerous ways which include the feelings of distress, disturbance and fatigue. According to Kavanagh (2005), stress is defined as "a nonspecific response of the body to a stimulus or event'". In an organization it is a situation where workers find it hard to adapt themselves to the work and hence the result is biological and psychological disorders (Hsieh et al., 2004). It is a feeling of discomfort that shows itself as a first level outcome of organization and job (Parker and Decottis, 1983). A variety of studies regarding stress have been conducted by different researchers around the world. It has been found to be a phenomenon that is bound to happen (White, 2006). It forces a person to deviate from his/her normal 
behavior (Beehr, 1976), feel exhaustion and ultimately lead to fatal diseases (Wofford et al., 1999).

\section{Symptoms}

Stress reveals itself in a variety of ways. A person may experience headache, anxiety, insomnia, recurring cold or flu and a feeling of frustration, etc. (NIOSH, 1999). The prolonged stress may impair the body's immunity system, raise the blood pressure and eventually result in hypertension, abnormal functioning of adrenal gland, tiredness and weakness of muscles, disorder in digestive system, dizziness and disturbances of sleep habit (Palmer and Dryden, 1994). The causes of stress in different research findings have been reported to include work overload, burden of responsibility, role ambiguity, role conflict, financial insecurity, lack of feedback, coping with sudden change, etc.

\section{Turnover Intentions}

Turnover "typically refers to the separation of an employee from the firm" (Naumann, 1992) whereas turnover intention is the deliberate response to leave any organization (Tett and Mayer, 1993). A consideration of extensive number of factors, has been found to be helpful for understanding employee turnover (Ongori, 2007) which include the work environment, tasks, duties and responsibilities assigned, communication, compensation etc. "Turnover is animportant issue for management, particularly in the tight labour markets prevalent at the turn of this century" (Batt and Valcour, 2003).

\section{Job Stress and Turnover Intentions}

Turnover may be the consequence of numerous factors but stress is considered to be the most important one (Leontaridi and Ward, 2002). Stress is the outcome of tensions and according to Cote and Morgan (2002), it can aggravate the employee turnover. The job-related tension badly influences job satisfaction that can lead to high turnover intentions (Kemery et al., 1987). The mental stress enhances the turnover intention. On the other hand, leaving intentions reduce in case of work satisfaction (Otis and Pelletier, 2005). There has been a close relationship between stress levels and intentions to leave (Leontaridi and Ward, 2002). Job stress is directly related to turnover intentions (Williams, 2003). Greater stress increases the ratio of employees' intensions to quit their job (Kavanagh, 2005; Cropanzano et al., 2003). "The amount of stress has a significant positive effect on turnover intention" (Layne et al., 2004). Hence we posit our first hypothesis as:

H1: Stress is directly related to the employees' turnover intentions

\section{Work Overload and Turnover Intentions}

"Workload refers to the amount of work that is allocated to an employee to do" (Qureshi et al., 2012). Work overload has a significant impact on work exhaustion (Ahuja et al., 2007). In an increasingly competitive environment, work overload is not an uncommon issue faced by most of the employees. It is considered to be a real problem in almost every organization (Altaf and Awan, 2011). The cause of stress happens to be the work overload resulting from time constraint and complexity of work (Mazloum et al., 2008). Burnout is the consequence of lesser job satisfaction (Nirel et al., 2008) and increased withdrawal of retained employees would be obvious in job dissatisfaction (Sheridan and Abelson, 1983). A direct relationship has been found between work load, stress and turnover intentions (Wefald et al., 2008). Hence we posit our second hypothesis as:

\section{H2: Work Overload is Directly Related to Turnover Intentions}

\section{Working Environment and Turnover Intentions}

Poor working conditions are reported to be a crucial factor for high turnover intentions (Milman, 2002). The flexible work arrangements result in higher job satisfaction which in turn paves way for reduced quitting intentions (Mcnall et al., 2010). The guts of supervision had a drastic effect on turnover intentions, in different organizations (Brannon et al., 2007). Absence of proper supervision and appropriate support from the authority towards accomplishment of assigned tasks will be instrumental in causing high stress and intentions to leave (Yahaya et al., 2009). Hence we posit our third hypothesis as:

\section{H3: Work environment has a significant impact on turnover intentions}

\section{Data Source and Methodology}

This research was based on primary data that was collected through a questionnaire designed on a five point Likert-scales having 26 items for measuring the independent and dependent variables i.e., job stress, work overload, work environment and employees turnover intentions. This survey was conducted in the private educational sector of Pakistan. More than 220 employees from about 15 private institutions were randomly selected. One hundred and seventy six responses were received which showed a response rate of $79 \%$. Most of the respondents were teachers.

The instrument used for the measurement of these variables was adopted from the study of Qureshi et al. (2012). 


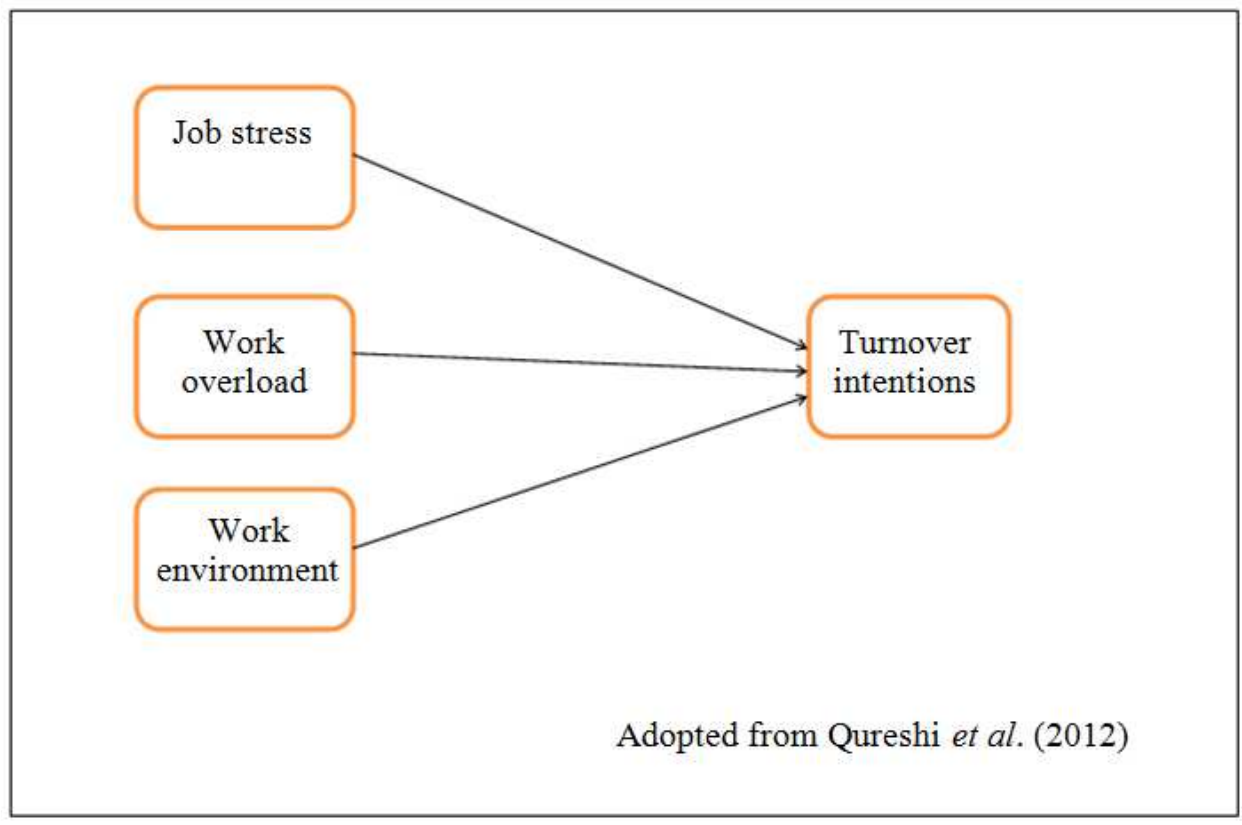

Fig. 1. Conceptual framework

The respondents were provided with 26 items with a number of indicators. The 5 points interval rating scale had the highest value of 5 and lowest value of 1 .

The Cronbach'salpha reliability test was conducted which proved the reliability of instrument with Cranbach's value of 0.8 . The conceptual model of the research is represented in Fig. 1.

\section{Results and Discussion}

\section{Frequencies}

Among the 176 respondents, 129 were the female and 47 were the male with the percentage of $73.3 \%$ and $26.7 \%$ respectively. The reason for higher ratio of females is common in Pakistan. Lots of young females prefer to join private schools and colleges for earning. There are many reasons for such selection by young females such as less travel required (they mostly opt for institutions that are most near to them) and schools are believed to be the safest places for young females to work. Out of those, $74 \%$ were single and rest married, 48 were from different colleges and 128 from various schools with 162 teachers and 13 respondents from administrative staff.

\section{Descriptive Statistics}

The respondents were provided with the questionnaire constructed on Likert scale of 1-5.the minimum mean value among all the items of the questionnaire was found to be 1.8 whereas the maximum value was 4.13 . The minimum standard deviation was 0.86 and the maximum value was 1.32 .
Table 1. Correlations, means and standard deviations

\begin{tabular}{llll}
\hline Variables & Mean & $\begin{array}{c}\text { Standard } \\
\text { deviation }\end{array}$ & Correlations \\
\hline Job stress & 2.2798 & 0.78422 & $0.318^{* *}$ \\
Work overload & 2.5578 & 0.79040 & $0.299^{* *}$ \\
Work environment & 3.3201 & 0.56215 & $0.271^{* *}$ \\
\hline
\end{tabular}

Table 2. Model summary

\begin{tabular}{lllll}
\hline Model & R & R Square & $\begin{array}{l}\text { Adjusted } \\
\text { R Square }\end{array}$ & $\begin{array}{l}\text { Std. Error } \\
\text { of the Estimate }\end{array}$ \\
\hline 1000 & $0.388^{\mathrm{a}}$ & 0.15 & 0.135 & 0.61613 \\
\hline
\end{tabular}

\section{Correlation Analysis}

The mean values of $2.2798,2.5578$ and 3.3201 for job stress, work overload and work environment respectively whereas the standard deviations are evident as $0.784,0.790$ and 0.562 for the three respectively.

The coefficient of correlation shows the degree of association between the variables (Table 1). In case of job stress and turnover intentions, its value is 0.318 which shows a positive and direct relationship between the two, thus increase in job stress will increase the turnover intentions. The positive correlation of 0.299 between work overload and turnover intentions again depicts a direct relationship showing that these variables move in the same direction.

\section{Model Summary}

The $\mathrm{R}^{2}$ value shows the overall impact of independent variables on the dependent variable (Table 2). The adjusted $\mathrm{R}^{2}$ value is 0.135 which means that $13.5 \%$ change in dependent variable i.e. turnover intentions, is 
brought about by the independent variables. In other word, antecedents of turnover intentions considered in this study account for $13.5 \%$ change in turnover intentions of employees.

\section{Regression Analysis}

Our first hypothesis that job stress is directly related to employees' turnover intentions is proved right from the results. The beta value for job stress is 0.166 with level of significance of 0.039 . Thus, our first hypothesis is accepted. The same result was obtained in a similar study conducted in the textile sector (Qureshi et al., 2012). Table 3 shows the regression analysis results.

The beta value for work overload is 0.098 . Here the level of significance (p) is greater than 0.05 which shows that there is no impact of work overload on turnover intentions. Thus our second hypothesis that work overload is directly related to turnover intentions is rejected. This is due to the fact that people in Pakistan are forced to accept and perform any sort of work because of the weak financial positions and high levels of unemployment. To earn their living, they accept even loads of work and do not find themselves in a position to leave their jobs.

The third hypothesis that there is a significant relationship between work environment and turnover intentions is also significant $(b=0.230, p<0.05)$. Here again, our hypothesis is accepted. However, to our surprise, the relationship between work environment and turnover intentions was not negative. For that authors develop several arguments; first, weak financial position of people may be the culprit, forcing people to work under poor working conditions. Secondly, Pakistan being a developing economy, most of the people is unaware of their rights at workplace. Third, most of workforce in private institutions comprises women (as evidenced by the sample), young women find it harder to leave jobs and pursue more attractive opportunities. Post-tests have also proved that when controlled for females, the relationship of work environment was negative with turnover intentions.

Table 3. Regression analysis

\begin{tabular}{llllll}
\hline & \multicolumn{2}{l}{$\begin{array}{l}\text { Unstandardized } \\
\text { coefficients }\end{array}$} & $\begin{array}{l}\text { Standardized } \\
\text { coefficients }\end{array}$ & \\
& -------------- & & \\
Model & B & Std. Error & Beta & T & Sig. \\
\hline 1(Constant) & 1.284 & 0.292 & 0.000 & 4.400 & 0.000 \\
Job Stress & 0.166 & 0.080 & 0.196 & 2.081 & 0.039 \\
Work overload & 0.098 & 0.080 & 0.117 & 1.235 & 0.219 \\
Work environment & 0.230 & 0.086 & 0.195 & 2.670 & 0.008 \\
\hline
\end{tabular}

a. Dependent Variable: Turnover Intentions

\section{Conclusion}

The results of the study revealed that job stress is one of the major factors that influence the employees' turnover intentions. The excessive pressure and nervous tension make the employees think to leave an organization. The work load may not be the source of quitting as is evident from the study. This mainly is so because people in Pakistan are out of jobs. Very few attractive opportunities are available. The level of unemployment and poverty is increasing day by day. To earn their living, people are forced to accept any kind of job even then where they are not fairly paid. They have no other choice than to accept whatever they are asked to do at their jobs. This is the reason that even under excessive workload; these people have no intent to leave. The work environment is another factor which may make employees thinks to stay with the organization or leave. A healthy and relaxed work environment would help in employee's retention and ultimately reduced turnover intentions.

\section{Recommendations/Implications for Practice}

For employee retention it is necessary for the managers to consider the factors that serve as stressors for the workers. The focus should also be on creating a friendly atmosphere at work place. This will enhance the satisfaction of employees resulting in better performance. Moreover, the government should design policies to regulate such a service structure that can provide guidelines to be followed regarding the work load, facilities at work, compensation and benefits etc. Though work load is not reported to be contributing to the turnover intentions in this study but it is an established fact that it increases stress which may ultimately result in turnover. So these issues require significant and tactful attention as future of nations is associated with educational institutions. These institutions can play their part in nations' development if they are being run by satisfied employees and for employee satisfaction the variables of this study deserve proper heedfulness.

\section{Limitations of Study and Direction for Future Research}

This study is focused on a single sector with a small sample size. It may have low generalizability. More work needs to be done in order to have greater generalizability of the findings. Furthermore, the data collected were only 176 samples. A larger sample size should increase the confidence of research findings.

This research was conducted by gathering data from private schools where the majority of teaching staff comprises females. However, other institution where there is more balanced or male majority staff, results could be different. Other industries should also be tested 
on the given model to test the validity of model across different industries. Besides three predictors used in this study, other variables should be incorporated and tested to increase the overall comprehensiveness of model.

\section{Funding Information}

This research is not funded by any agency or authority.

\section{Authors Contribution}

Both the authors have contributed equally to this research.

\section{Ethics}

There is no ethical issue related to this research work.

\section{References}

Ahuja, M.K., K.M. Chudoba, C.J. Kacmar, D.H. McKnight and J.F. George, 2007. IT road warriors: Balancing work-family conflict, job autonomy and work overload to mitigate turnover intentions. MIS Q., 1-17.

Altaf, A. and M.A. Awan, 2011. Moderating affect of workplace spirituality on the relationship of job overload and job satisfaction. J. Bus. Ethics, 104: 93-99. DOI: $10.1007 / \mathrm{s} 10551-011-0891-0$

Anderson, R., 2003. Stress at work: The current perspective. Perspectives Public Health, 123: 81-87. DOI: $10.1177 / 146642400312300211$

Batt, R. and P.M. Valcour, 2003. Human resources practices as predictors of work-family outcomes and employee turnover. Industrial Relations: J. Econ. Society, 42: 189-220.

DOI: $10.1111 / 1468-232 X .00287$

Beehr, T.A., 1976. Perceived situational moderators of the relationship between subjective role ambiguity and role strain. J. Applied Psychol., 61: 35-40. DOI: $10.1037 / 0021-9010.61 .1 .35$

Biron, C., J.P. Brun and H. Ivers, 2008. Extent and sources of occupational stress in university staff. Work, 30: 511-522. PMID: 18725713

Brannon, D., T. Barry, P. Kemper, A. Schreiner and J. Vasey, 2007. Job perceptions and intent to leave among direct care workers: Evidence from the better jobs better care demonstrations. Gerontologist, 47: 820-829. DOI: $10.1093 /$ geront/47.6.820

Cote, S. and L.M. Morgan, 2002. A longitudinal analysis of the association between emotion regulation, job satisfaction and intentions to quit. J. Organizational Behavior, 23: 947-962. DOI: 10.1002/job.174
Cropanzano, R., D.E. Rupp and Z.S. Byrne, 2003. The relationship of emotional exhaustion to work attitudes, job performance and organizational citizenship behaviors. J. Applied Psychol., 88: 160-169. DOI: 10.1037/0021-9010.88.1.160

Hsieh, H.L., L.C. Huang and K.J. Su, 2004. Work stress and job performance in the hi-tech industry: A closer view for vocational education.

Kavanagh, J., 2005. Stress and performance a review of the literature and its applicability to the military. DTIC Document.

Kemery, E.R., K.W. Mossholder and A.G. Bedeian, 1987. Role stress, physical symptomatology and turnover intentions: A causal analysis of three alternative specifications. J. Organizational Behavior, 8: 11-23. DOI: 10.1002/job.4030080103

Layne, C.M., T.H. Hohenshil and K. Singh, 2004. The relationship of occupational stress, psychological strain and coping resources to the turnover intentions of rehabilitation counselors. Rehabilitation Counseling Bull., 48: 19-30. DOI: $10.1177 / 00343552040480010301$

Leontaridi, R.M. and M.E. Ward-Warmedinger, 2002. Work-related stress, quitting intentions and absenteeism.

Mazloum, A., M. Kumashiro, H. Izumi and Y. Higuchi, 2008. Quantitative overload: A source of stress in data-entry VDT work induced by time pressure and work difficulty. Industrial Health, 46: 269-280. DOI: 10.2486/indhealth.46.269

McNall, L.A., A.D. Masuda and J.M. Nicklin, 2009. Flexible work arrangements, job satisfaction and turnover intentions: The mediating role of work-tofamily enrichment. J. Psychol., 144: 61-81. DOI: $10.1080 / 00223980903356073$

Milman, A., 2002. Hourly employee retention in the attraction industry: Research from small and medium-sized facilities in Orlando, Florida. J. Retail Leisure Property, 2: 40-51. DOI: $10.1057 /$ palgrave.rlp.5090138

Naumann, E., 1992. A conceptual model of expatriate turnover. J. Int. Bus. Stud., 23: 499-531. DOI: $10.1057 /$ palgrave.jibs. 8490277

NIOSH, 1999. Stress at Work. U.S. National Institute for Occupational Safety and Health, DHHS (NIOSH) Publication Number 99-10.

Nirel, N., R. Goldwag, Z. Feigenberg, D. Abadi and P. Halpern, 2008. Stress, work overload, burnout and satisfaction among paramedics in Israel. Prehospital Disaster Med., 23: 537-546. PMID: 19557971

Ongori, H., 2007. A review of the literature on employee turnover. Afr. J. Bus., 1: 49-54. 
Otis, N. and L.G. Pelletier, 2005. A motivational model of daily hassles, physical symptoms and future work intentions among police officers. J. Applied Social Psychol., 35: 2193-2214.

DOI: $10.1111 /$ j.1559-1816.2005.tb02215.x

Palmer, S. and W. Dryden, 1994. Counselling for Stress Problems. 1st Edn., Sage, London, ISBN-10: 144626467X, pp: 262.

Parker, D.F. and T.A. DeCotiis, 1983. Organizational determinants of job stress. Organizational Behavior Human Performance, 32: 160-177. DOI: $10.1016 / 0030-5073(83) 90145-9$

Qureshi, M.I., R.A. Jamil, M. Iftikhar, S. Arif and S. Lodhi et al., 2012. Job Stress, workload, environment and employees turnover intentions: Destiny or choice. Arch. Sci., 65: 230-241.

Sheridan, J.E. and M.A. Abelson, 1983. Cusp catastrophe model of employee turnover. Acad. Manage. J., 26: 418-436. DOI: 10.2307/256254

Tett, R.P. and J.P. Meyer, 1993. Job satisfaction, organizational commitment, turnover intention and turnover: Path analyses based on meta-analytic findings. Personnel Psychol., 46: 259-293.

DOI: $10.1111 /$ j.1744-6570.1993.tb00874.x
Wefald, A.J., M.R. Smith, T.C. Savastano and R.G. Downey, 2008. A structural model of workload, job attitudes, stress and turnover intentions. Kansas State University.

White, R.A., 2006. Perceived stressors, coping strategies and burnout pertaining to psychiatric nurses working on locked psychiatric units. MSc Thesis, Department of Nursing, Eastern Michigan University, Michigan.

Williams, A., 2003. Job stress, job satisfaction and intent to leave employment among maternal-child health nurses. Marshall University Huntington.

Wofford, J., V.L. Goodwin and P.S. Daly, 1999. Cognitive-affective stress propensity: A field study. J. Organizational Behavior, 20: 687-707.

DOI: $10.1002 /($ SICI) 1099 1379(199909)20:5<687::AID-JOB926>3.0.CO;2-5

Yahaya, A., N. Yahaya, K. Arshad, J. Ismail and S. Jaalam et al., 2009. Occupational stress and its effects towards the organization management. J. Social Sci., 5: 390-397.

DOI: $10.3844 /$ jssp.2009.390.397 